shoulder with intorsion of the upper limbs. She also showed athetoid movements of the toes. In addition to these spontaneous movements, examination revealed a dysarthria, phasic nystagmus (more marked to the left owing to an unwillingness to look to the right) and a severe gait ataxia.

The abnormal spontaneous movements gradually decreased over the next 24 hours, and by 72 hours after admission had completely vanished. At this time her nystagmus had also stopped, although her ataxia had now changed in type and was closely related to being observed.

A drug screen was taken at the time of admission and this showed a plasma concentration of $88 \mathrm{mg} /$ litre of phenobarbital (comatose level usually being greater than $75 \mathrm{mg} /$ litre), there was no phenytoin detected, and only a trace of diazepam. On questioning the patient later she admitted that she had stolen the phenobarbital from a friend who was epileptic, and that the only diazepam she had taken was her normal dose $(15 \mathrm{mg} /$ day $)$ that she had been taking for several months.

\section{Discussion}

It seems unequivocal in this patient that the chorea and torsion dystonia noted in the recovery phase from her phenobarbital overdose were directly related to toxic levels of this drug. It is of course well recognized that anticonvulsants, when taken in excess, are able to produce a variety of dyskinesias. Chorea and dystonia, however, have only been recorded in patients who have grossly elevated serum levels of phenytoin, and have never been reported with other anticonvulsants alone. A recent review (Chadwick, Reynolds and Marsden, 1976) states categorically that "diphenylhydantoin, but not other anticonvulsants, may cause orofacial dyskinesias, limb chorea and dystonia in intoxicated patients'. The present case demonstrates that both chorea and torsion dystonia may be caused by phenobarbital alone.

\section{Acknowledgments}

I am grateful to Dr J. D. H. Slater for allowing me to report this case, and to Dr M. J. G. Harrison for his help.

\section{References}

Chadwick, D., Reynolds, E.H. \& Marsden, C.D. (1976) Anticonvuisant-induced dyskinesias: a comparison with dyskinesias induced by neuroleptics. Journal of Neurology, Neurosurgery and Psychiatry, 39, 1210.

\title{
Cerebral haemorrhage in haemophilia
}

\author{
Michael BENNETT* \\ M.B., B.S., M.R.C.P.
}

\author{
JohN A. Sills \\ M.B., B.Chir., M.R.C.P., D.C.H.
}

The Royal Infirmary and Royal Hospital for Sick Children, Edinburgh

\begin{abstract}
Summary
A young male haemophiliac child is here described in whom intracerebral haemorrhage required craniotomy and the subsequent insertion of a ventriculo-peritoneal shunt. These procedures can now be attempted in severe haemophilia $A$ because of the ease in clotting factor replacement therapy.
\end{abstract}

\section{Introduction}

The occurrence of a cerebral haemorrhage in a haemophiliac has nearly always a fatal outcome (Silverstein, 1960). Recently, however, there has been a rapid advance in the treatment of haemophilia

\footnotetext{
* Present address: Department of Haematology, The Royal Free Hospital, London NW3 2QG.
}

with the development of potent small volume human factor VIII replacement therapy. Here, now, is described how such modern therapy was applied to a haemophiliac with cerebral haemorrhage in an attempt to improve the prognosis.

\section{Case report}

The patient was diagnosed as having haemophilia $A$ at the age of nine months. Bruising had been notice during the preceding two months. The biological factor VIII level was $2 \%$, factor IX level was $96 \%$ and the bleeding time (Ivy) was normal at $3 \mathrm{~min}$. The platelet count was $480 \times 10^{9} / 1$ and the prothrombin time was normal. There was no family history of a bleeding diathesis. Over the next three 
months treatment with cryoprecipitate was required for minor bruising and bleeding episodes. At the age of 13 months he fell and sustained a bruise on his right forehead. He was admitted to hospital three days later with vomiting, drowsiness and irritability. On examination he was febrile with neck retraction and a full pulsatile fontanelle. No papilloedema or retinal haemorrhages were noted, but he had a right hemiparesis with return of the primitive grasp reflex. Echo-encephalography showed a right-to-left shift of $1.5 \mathrm{~cm}$. A lumbar puncture with factor VIII cover yielded a blood-stained CSF with a raised cell count $\left(110 / \mathrm{mm}^{3}\right.$, a mixture of polymorphs and lymphocytes), a low glucose ( $2 \mathrm{mmol} / \mathrm{l})$, and a raised protein of $7 \mathrm{~g} / \mathrm{l}$. These findings suggested meningitis and he was treated with antibiotics initially until the culture of CSF was reported negative. Satisfactory factor VIII levels were maintained with the use of a human freeze-dried concentrate (Fig. 1). Each vial contained between 270 and 320 units and was reconstituted with water to a volume of $10 \mathrm{ml}$.

Computerized axial tomography (EMI scan) $48 \mathrm{hr}$ after admission showed a right parieto-occipital haematoma (Fig. 2). The child's temperature settled, shift on the encephalogram reduced to $3 \mathrm{~mm}$ and his condition improved with resolution of the hemiparesis over the next three days. He remained irritable, however.

On the seventh day after admission the parietal haematoma was removed through a right parietal trephine under general anaesthesia and continued factor VIII cover. Haemostasis was excellent duriffg this procedure. The haematoma was firm and wefl circumscribed. It was removed piecemeal with pituitary rongeurs and suction. The child made good postoperative recovery and was well until the eighth postoperative day when, despite continuegd adequate factor VIII replacement, he deteriorated with signs of raised intra-cranial pressure and ca further echo-encephalogram showed a recurrence $\overrightarrow{\theta f}$ a right-to-left shift.

After some improvement following diuresis with intravenous mannitol he continued to deteriorate and a further EMI scan (Fig. 3) showed recurrenge of the haematoma, extension into the right laterang ventricle and the development of hydrocephalus. $\perp$

A Pudenz Heyer ventriculo-peritoneal shunt whes then inserted through a left parietal burr hole under factor VIII cover. His condition again improved and his wounds healed well. Factor VIII was discontinued 16 days after his second operation. The child wẳ then discharged home with no neurological sequelat or apparent intellectual deterioration.

Two weeks later he was readmitted with suspected recurrent hydrocephalus. Ventricular puncture however, showed no significant rise in pressure. He then had two further episodes of raised intracringal pressure which responded to diuretics and 10 ⿶ays after admission he was well with no neurologica defect. Factor VIII replacement was discontinue d

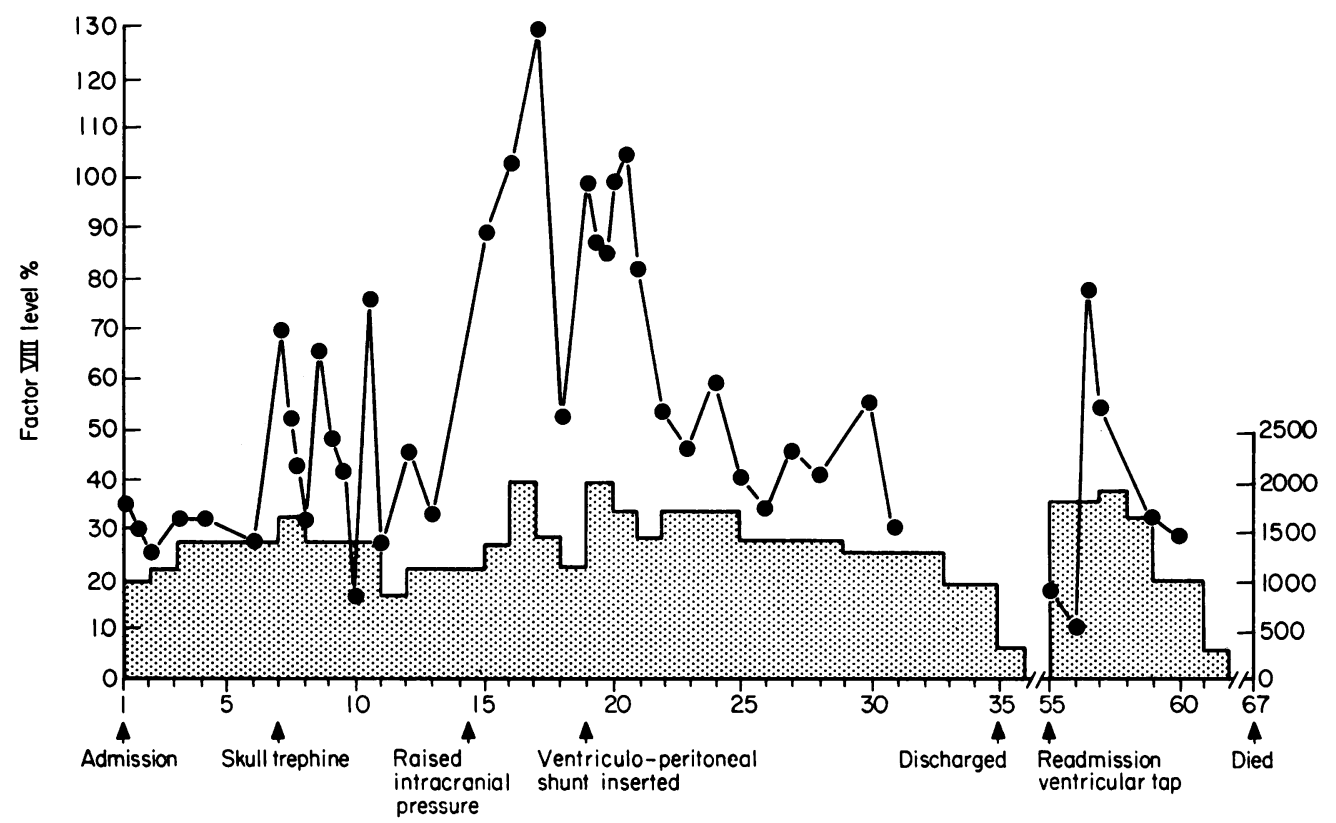

FIG. 1. Relation of total amount of factor VIII units given per day to factor VIII level attained. 


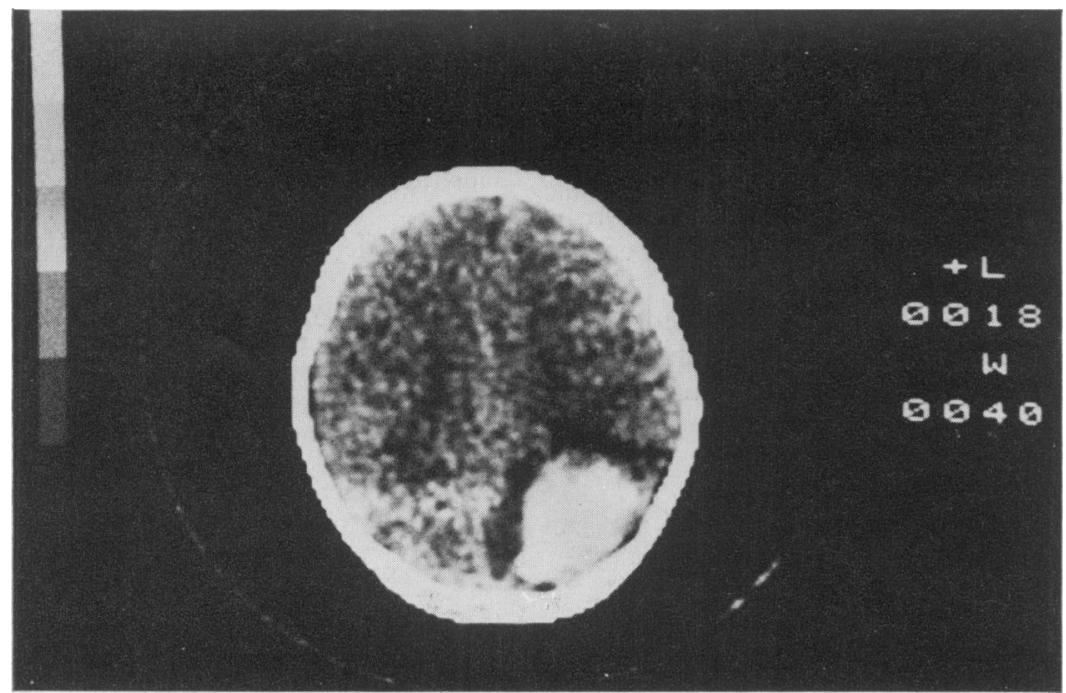

FIG. 2. EMI scan showing a lesion of haematoma density located in the right parietooccipital region.

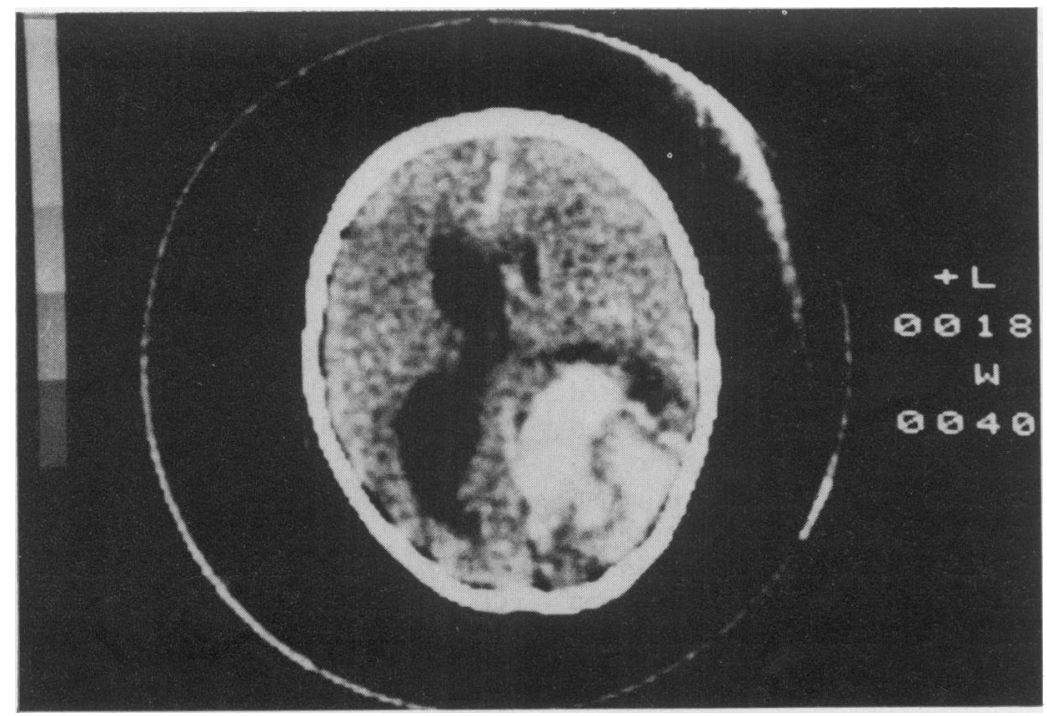

FIG. 3. EMI scan showing a lesion similar to that in Fig. 2 but with enlargement of the ventricles.

on the sixth day of admission. Subsequently he sustained a further massive intra-orbital haemorrhage with proptosis, no treatment was given and he became unconscious and died. Permission for a post-mortem examination was refused.

\section{Discussion}

Cerebral haemorrhage, although a well recognized complication of haemophilia, occurs infrequently and its prognosis is said to be poor (Silverstein, 1960). Insertion of a ventriculo-peritoneal shunt in a 
haemophilic child has previously been described (McCarthy and Coble, 1973).

The present case emphasizes that, with maintenance of adequate factor VIII levels, surgical intervention for cerebral haemorrhage can be undertaken without haemostatic problems. Although the ultimate prognosis was not affected here, neurosurgery should now be contemplated for this complication.

The use of the EMI scan is also illustrated here. This permits anatomical localization without invasive procedure and is of particular value in this situation.

\section{Acknowledgments}

We are grateful to Dr W. Morrice McCrae, Consultant Paediatrician, Dr S. H. Davies, Consultant Haematologist; and Mr J. F. Shaw, Consultant Neurosurgeon, for permissio to publish details of this case and to $\operatorname{Dr}$ A. A. Donaldson for the EMI scans. The Edinburgh Protein Fractionation Centre supplied the human freeze-dried concentrate.

\section{References}

MCCARTHY, J.W. \& CoBle, L.L. (1973) Intracranial haemor rhage and subsequent communicating hydrocephalus in $\vec{B}$ neonate with classical hemophilia. Pediatrics, 51, 122.

SilversteIN, A. (1960) Intracranial bleeding in hemophilia $\vec{\omega}$ Archives of Neurology, 3, 141.

\title{
The use of dilute hydrochloric acid and cimetidine to reverse severe metabolic alkalosis
}

\author{
B. J. RowlandS \\ M,B., F.R.C.S. \\ S. F. TINDALL* \\ M.B., F.R.C.S. \\ D. J. ElliotT \\ M.B., Ch.B., F.F.A.R.C.S. \\ Department of Surgery and Anaesthetics, Northern General Hospital, Sheffield, S5 7AU
}

\begin{abstract}
Summary
Two cases of severe metabolic alkalosis associated with gastric hypersecretion were successfully treated with dilute hydrochloric acid and a histamine $\mathbf{H}_{2}$ receptor antagonist given by intravenous infusion. This combined therapy with electrolyte replacement and suppression of gastric secretion is valuable in the control of this serious metabolic abnormality when conventional treatment is unsuccessful or contraindicated.

\section{Introduction}

Patients with gastric hypersecretion associated with Zollinger-Ellison syndrome may develop severe metabolic alkalosis due to large losses of hydrogen ion. The conventional management of this acid/base disturbance is the infusion of large volumes of sodium and potassium chloride which suppress renal acid excretion and increase renal alkali excretion

* Present address: Senior Surgical Registrar, Royal Hospital, Sheffield S1 3SR
\end{abstract}

(Kassirer, Berkman and Lawrenz, 1965; Schwartz? van Ypersele de Strihou and Kassirer, 1968). This is a slow process which relies on good renal function and in some clinical situations is inappropriate op. may be unsuccessful. This paper describes two cases of severe metabolic alkalosis in patients with gastric hypersecretion which were successfully treated with? dilute hydrochloric acid and a histamine $\mathrm{H}_{2}$-receptor antagonist, cimetidine.

\section{Case 1}

A 22-year-old female was admitted for investiga tion of dyspepsia. She was known to have congenitar heart disease, and at the age of 11 a Blalock Hanlon operation had been performed, following which shew had led a relatively normal life with some restriction in physical activity. For one year she had complainedo of abdominal pain associated with nausea andक vomiting. The pain was relieved by food and alkalis.? Barium meal examination had shown coarse gastric mucosal folds and multiple erosions in the second 